\title{
THE EFFECT OF HYPERCALCEMIA INDUCED BY CALCIFEROL UPON RENAL CONCENTRATING ABILITY ${ }^{1}$
}

\author{
By FRANKLIN H. EPSTEIN,2 MANUEL J. RIVERA, ${ }^{3}$ AND FRANK A. CARONE 4 \\ (From the Departments of Internal Medicine and Pathology, Yale University School of Medicine, \\ New Haven, Conn.)
}

(Submitted for publication July 3, 1958; accepted July 31, 1958)

Polyuria and loss of renal concentrating ability have frequently been observed in patients with hypercalcemia (1-8). It has not been clear whether the capacity of the kidneys to concentrate urine is selectively impaired by hypercalcemia or whether it is depressed together with many other renal functions as a result of substantial injury to and encroachment upon active renal parenchyma (9). In the present experiments the effects of hypercalcemia on renal function and morphology were studied in rats given large doses of calciferol (vitamin $D_{2}$ ) for several days. The results suggest that hypercalcemia and renal damage produced in this manner specifically impair renal concentrating ability. This functional defect is associated with alterations in the structure of the collecting tubules of the renal medulla.

\section{METHODS}

Eighteen male albino rats of the Sprague-Dawley strain, weighing about $300 \mathrm{Gm}$., were maintained on a measured diet of Purina Lab Chow and allowed to drink tap water ad libitum. Following initial determinations of blood urea nitrogen, urea clearance, phenolsulfonphthalein (PSP) excretion and maximum urinary osmolality, 200,000 units or 400,000 units of vitamin $D_{2}$ in peanut oil was injected subcutaneously daily for four days. At the end of this time, the same tests were repeated. The animals were then sacrificed by exsanguination from the abdominal aorta during pentobarbital anesthesia and the kidneys removed for morphologic examination. Eight rats served as controls, receiving only peanut oil for four days, with food intake limited to that taken by matched animals receiving vitamin $D_{2}$.

For the measurement of urea clearance, 0.2 to $0.3 \mathrm{ml}$. of heparinized blood was obtained from the tail. Rats

1 Aided by grants from the American Heart Association; the National Heart Institute, United States Public Health Service; and a contract (MD-116) with the Office of the Surgeon General, Department of the Army.

2 During the tenure of an Established Investigatorship of the American Heart Association.

3 Kellogg Foundation Fellow.

4 Fellow of the Life Insurance Medical Research Fund. were then stimulated to empty their bladders by making them sniff ether and placed in individual metabolism cages without food or water for 12 hours, when micturition was again stimulated and the urine collected. Urea was measured in blood and urine by the method of Conway (10). Following 12 hours of dehydration, $50 \mathrm{mU}$ of vasopressin in oil ${ }^{5}$ was injected subcutaneously and urine collected under oil for another 12 hours for the determination of maximum urinary osmolality $\left(U_{\max }\right)$. The osmolal concentration of this urine was measured cryoscopically using a Fiske osmometer after diluting $0.5 \mathrm{ml}$. of urine to $2.0 \mathrm{ml}$. with distilled water.

To measure phenol red (PSP) excretion, $0.03 \mathrm{mg}$. of commercial PSP dye was injected subcutaneously. Rats were then placed in individual metabolism cages with free access to drinking water and stimulated to void after two hours. Funnels and screens were rinsed with distilled water and the total volume brought to $25 \mathrm{ml}$. This was made alkaline with a few drops of concentrated $\mathrm{NaOH}$, filtered and read at $540 \mathrm{~m} \mu$ in a Coleman Jr. spectrophotometer.

Serum calcium was measured, after oxalate precipitation, by permanganate titration (11), or flame photometry using a Coleman Flame photometer with a special filter. ${ }^{6}$

\section{RESULTS (TABLE I)}

\section{Renal function}

During the four days when calciferol was administered, rats characteristically reduced their intake of food and lost considerable weight (average, $36 \mathrm{Gm}$.). At the conclusion of this period, the serum calcium had risen to hypercalcemic levels (average, $12.9 \mathrm{mg}$. per $100 \mathrm{ml}$.), which were somewhat higher in those animals getting 400,000 units per day than in those receiving half that dose.

Maximum urinary osmolality after vasopressin was strikingly diminished in every animal (from an average of 2,630 mOsm. per $\mathrm{Kg}$. to 1,625 mOsm. per $\mathrm{Kg}$.). The decrease in $U_{\max }$ could not be attributed to a solute diuresis, since the quantity of

\footnotetext{
${ }^{5}$ Kindly supplied as Pitressin ${ }^{\circledR}$ Tannate in Oil by Parke-Davis.

6 "Ca III filter," supplied by Baird Associates, Danvers, Mass.
} 


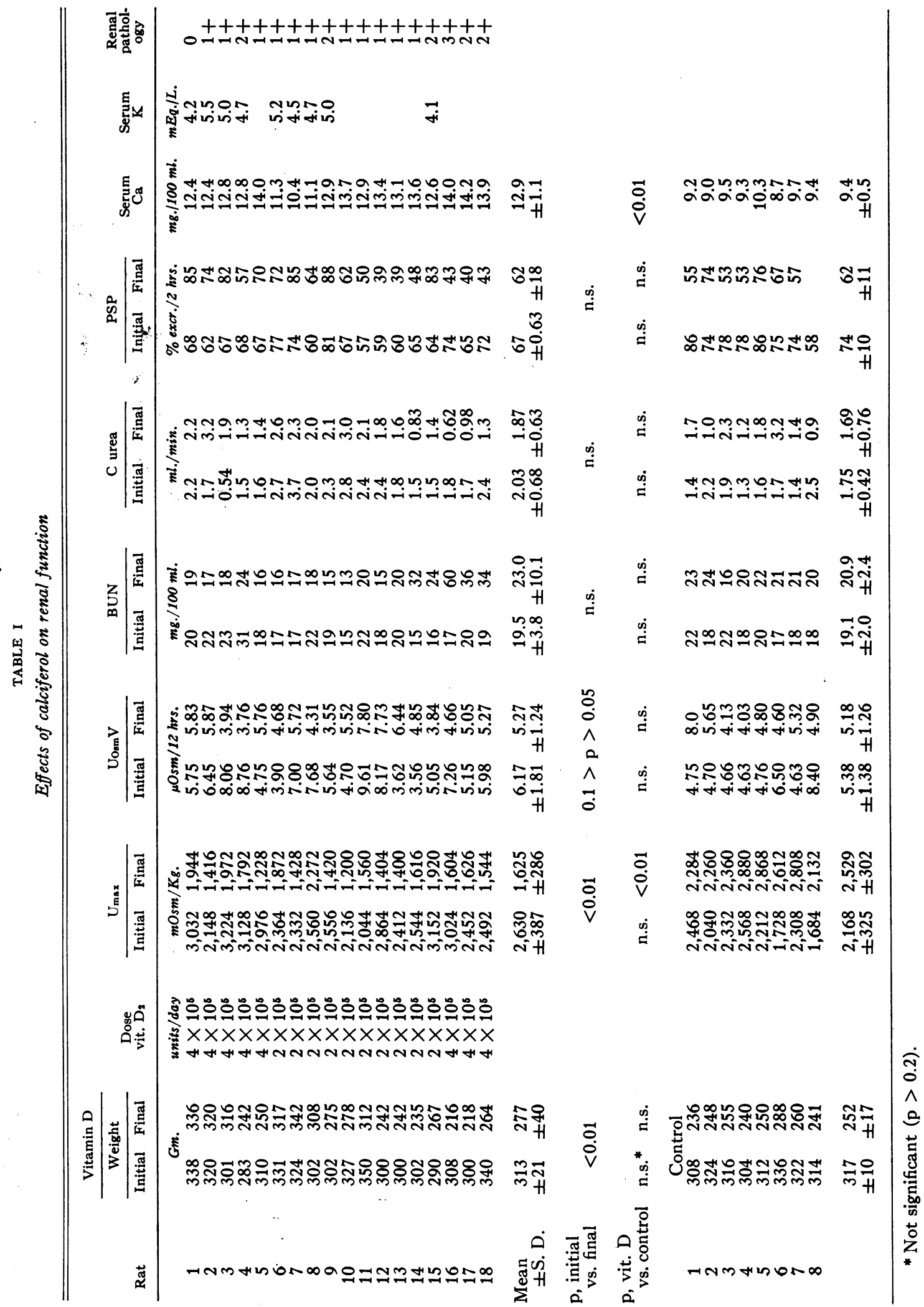




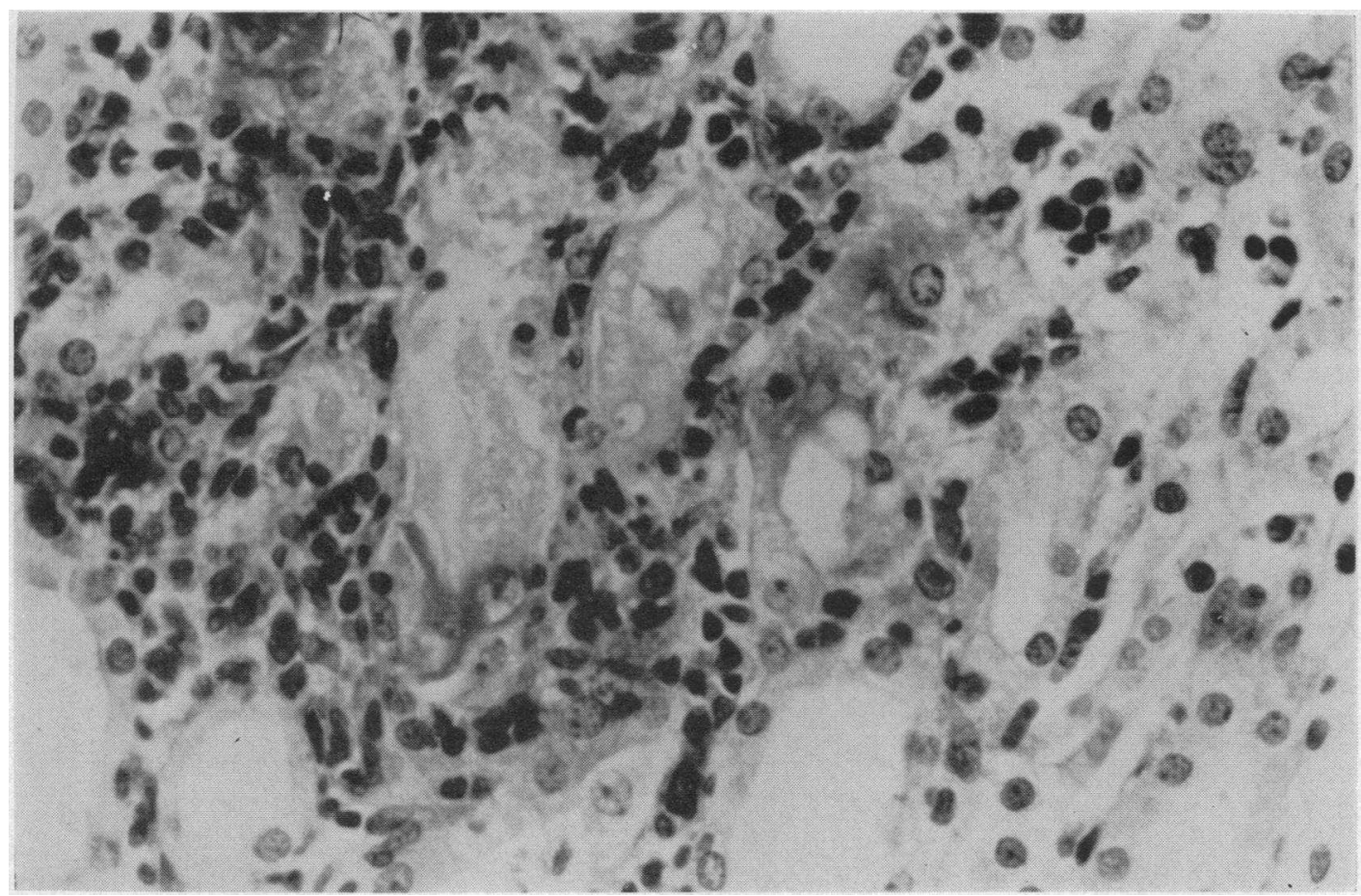

Fig. 1. Three Tubules in the Outer Medulla with Necrosis of the Epithelial Cells and an Infiltrate of Mononuclear Cells in the Intertubular Space

Rat 9, hematoxylin and eosin stain, $400 \times$.

solute excreted by hypercalcemic rats while under the influence of vasopressin was not greater than that excreted by the same animals before they received calciferol. Blood urea nitrogen rose in only 5 of 18 rats. In two-thirds of the animals the urea clearance was unchanged, rose, or fell less than 15 per cent. The average excretion of phenol red was 67 per cent in two hours prior to the injection of vitamin $\mathrm{D}_{2}$ and 62 per cent after treatment; only 7 of the 18 rats had decreases which exceeded 10 per cent of the injected dose of PSP.

Serum potassium, sodium and chloride were normal in 10 hypercalcemic rats in which they were measured.

In four rats given 400,000 units of calciferol daily for four days, the intake of potassium was increased by substituting a 1 per cent solution of $\mathrm{KCl}$ for drinking water. Results in these animals were entirely simliar to those obtained without potassium supplementation.

Eight pair-fed control animals received daily injections of peanut oil for four days. Weight loss in this group was comparable to that sustained by the most anorectic rats receiving vitamin $D_{2}$. Maximum urinary osmolality of these animals did not change or rose slightly. Blood urea nitrogen (BUN), urea clearance and PSP excretion were likewise not appreciably affected by dietary restriction and control injections of peanut oil.

\section{Renal morphology}

Anatomical changes in rats receiving calciferol were classified as minimal $(1+)$, moderate $(2+)$ or severe $(3+)$, depending upon the number and extent of the lesions. Changes were chiefly localized to the collecting ducts in the medulla. Even in the most severe $(3+)$ lesions, not more than 10 per cent of nephrons were involved. In those graded as $1+$ only a rare tubule showed morphological changes. In one instance (Animal No. 1, Table I) no specific changes were detected in the kidney, even though hypercalcemia and impaired renal concentrating ability existed. Most kidneys showed minimal lesions which were focal, involving only a short segment of the collecting tubule. The essential alterations were necrosis 


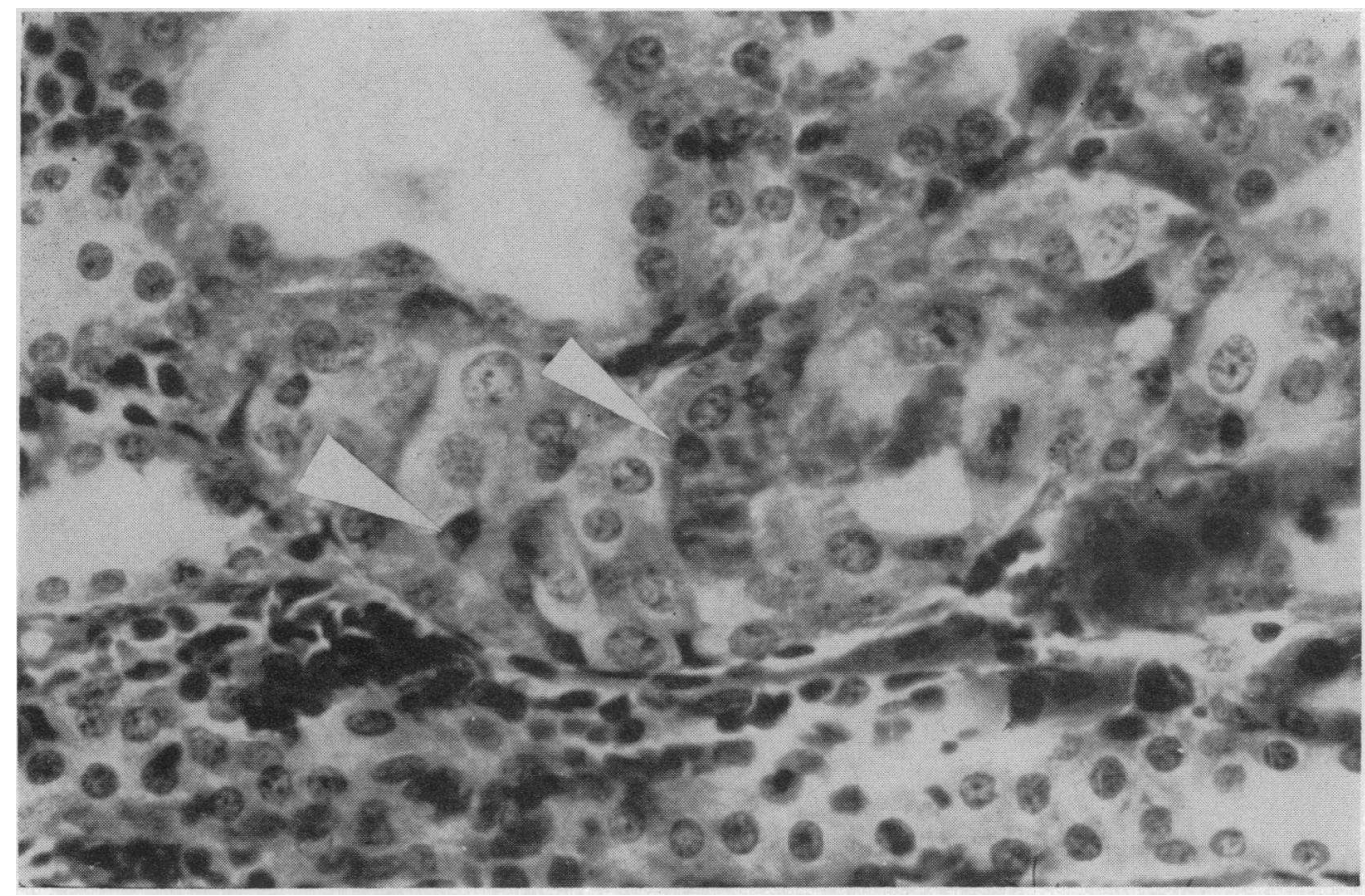

Fig. 2. Focal Proliferation of Epithelial Cells in a Segment of Collecting Tubule in the Outer Medulla Producing Complete Obstruction of the lumen

The intercalated cells (arrows) have small pyknotic nuclei and dark cytoplasm with pointed projections. A mitosis can be seen to the right near the luminal center. The dark, irregular masses among the regenerating cells stained positively for calcium. Rat 4 , hematoxylin and eosin stain, $400 \times$.

of tubular epithelial cells and proliferation by young regenerating cells (Figures 1 through 3 ). Some epithelial cells were calcified (Figure 4) and frequently irregular masses of calcium, demonstrable by special staining, were present among the clusters of degenerating and necrotic tubular cells (Figure 2). These casts contained minute amounts of iron and were periodic-acid-Schiff (PAS) positive, as in the report of Eisenstein and Groff (12). Occasionally, short segments of basement membrane were calcified and where the epithelial alterations were most intense dissolution of the basement membrane could be demonstrated by special staining methods (Figure 3 ). The proliferative response associated with this injury involved both the tubular epithelial cells and the connective tissue of the intertubular stroma (Figure 3) which at times produced a localized "granuloma" incorporating several tubules. On microdissection, it was extremely difficult to sepa- rate the tubular segments caught in these masses of granulation tissue. However, only segments of the collecting tubules in the outer medulla were obstructed by this interstitial granulation tissue, since tubular dilatation was restricted to proximal segments of the collecting system which in some instances extended to distal convolutions and terminal portions of the ascending limb of Henle's loop. In kidneys with minimal lesions, microdissection revealed no morphological alterations in segments of the nephron proximal to the collecting system except for occasional ascending limbs of Henle's loop and distal convolutions which had an increased number of intracellular lipoid droplets as compared to control animals when stained with flaming red.

In some instances the proliferative response in the tubules was so intense that masses of cells extended into the lumens as polypoid buds and frequently the tubules were completely occluded by 


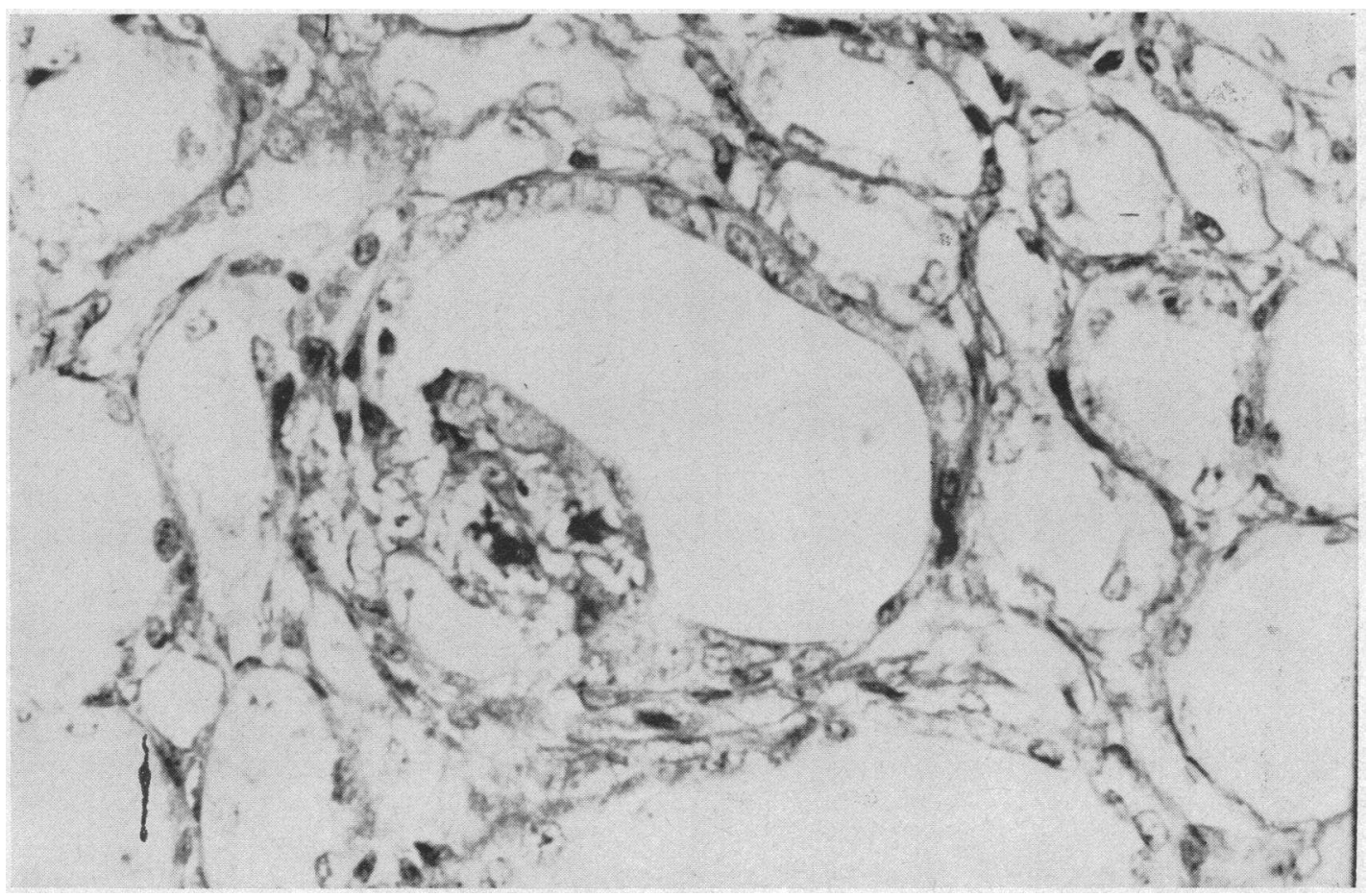

Fig. 3. Collecting Tubule in Outer Medulla Showing Focal Epithelial Necrosis and Regenerative Proliferation with Dissolution of the Basement Membrane and Growth of Granulation Tissue in the Interstitial Stroma

Rat 15, periodic-acid-Schiff, $400 \times$.

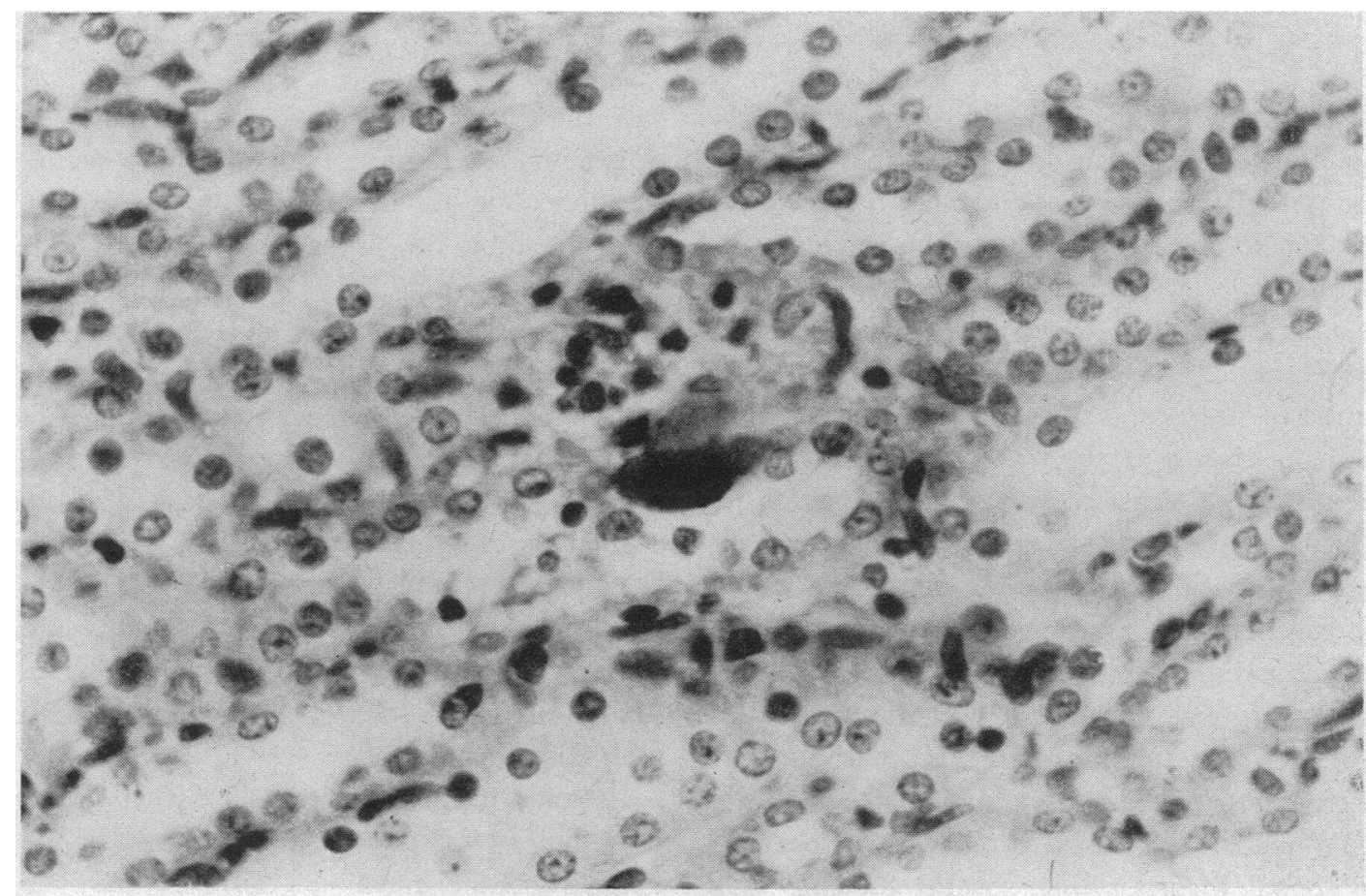

Fig. 4. Focal Calcification of Several Epithelial Cells and the Subjacent Basement Membrane in a Collecting Tubule

Rat 6, hematoxylin and eosin stain, $400 \times$. 


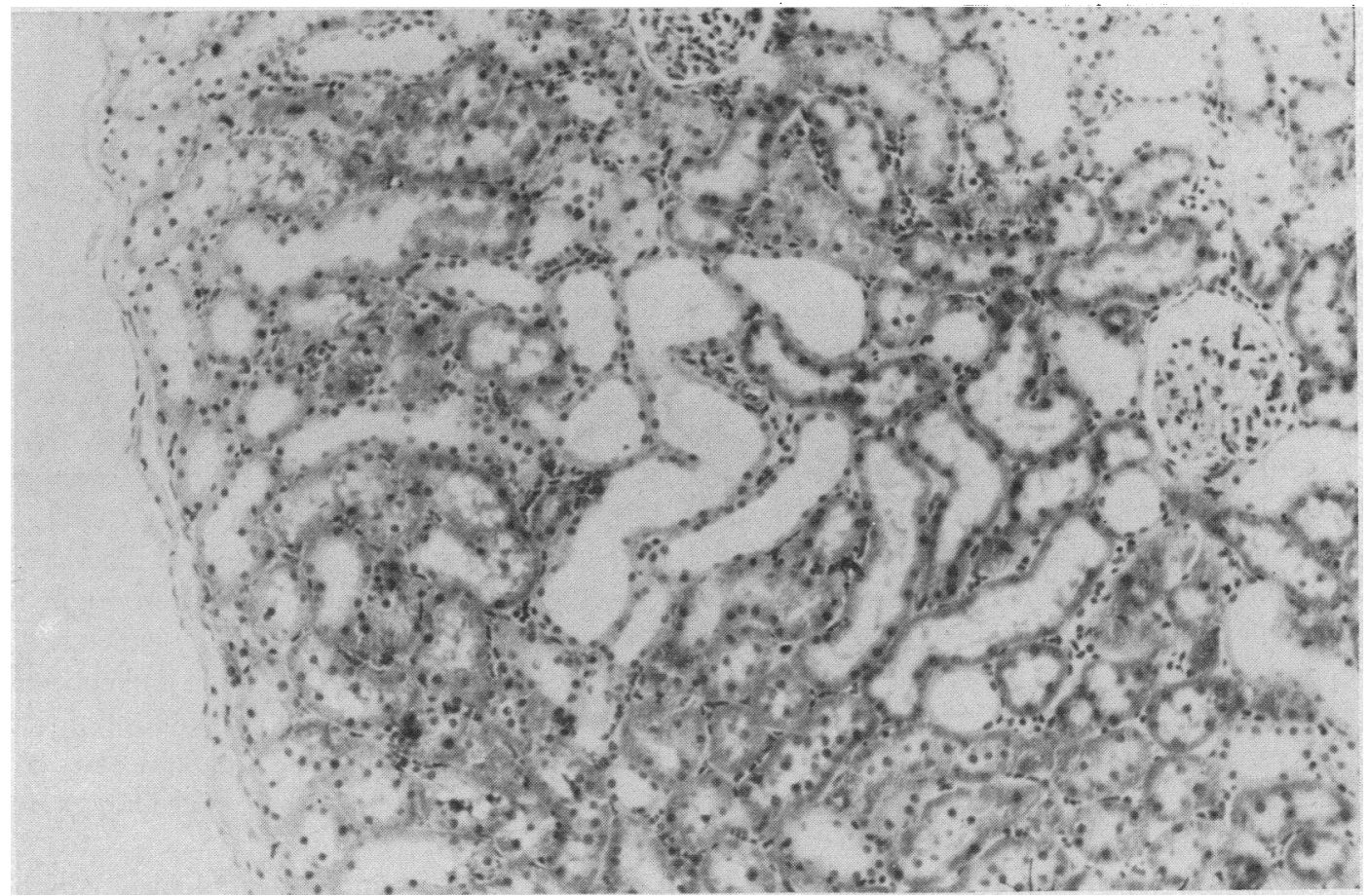

Fig. 5. Dilatation of Proximal Segments of the Collecting Tubules in the Cortex

There are no alterations in more proximal portions of the nephron. Rat 9 , hematoxylin and eosin stain, $200 \times$.

masses of regenerating epithelial cells (Figure 2). This also resulted in dilatation of the nephron proximally (Figure 5 ).

The location and distribution of the tubular changes were rather specific and of particular interest. Most lesions occurred in the outer medulla and involved small clusters of several neighboring tubules. In the cortex, the straight tubules in the medullary rays, particularly in the inner cortex, also showed changes. Many of the damaged segments were identified as collecting tubules by the presence of intercalated cells (Figure 2). Where the tubular lesions occurred in clusters, segments of the nephron other than collecting tubules could have been involved; however, tubules recognizable as part of the collecting system showed the most severe changes.

Deposits of calcium were recognizable in the masses of necrotic and proliferating epithelial cells or the corresponding basement membranes. Although, at times, calcium extended for short distances into the intertubular stroma from the calcified basement membranes, isolated deposits in the interstitium were absent.
Only a few animals showed severe renal lesions involving all segments of the nephron. The tubular epithelial alterations were similar to those in the collecting system, and in addition, these kidneys revealed calcification of the basement membranes of proximal convoluted tubules and the glomerular capsules. It should be stressed that even in animals with lesions of moderate $(2+)$ degree, only a few nephrons were involved and that the remainder were normal morphologically, employing both histological and microdissection techniques.

In only a few kidneys vascular changes induced by calciferol were present and these were minimal, involving only the large arteries. They produced no detectable reduction in the size of the lumen and could not account for the morphological and physiological alterations observed in these kidneys.

\section{DISCUSSION}

Vitamin D intoxication has long been known to produce structural changes in the kidneys and other organs and severe impairment of renal function (see Reference 2 for review). The degree 
and character of damage to renal parenchyma depend upon the size of the dose and the duration and route of administration. Thus, doses of calciferol much smaller than those used in the present experiments produced severe periarteritis and calcium deposits in vessel walls and in glomeruli when the sterol was given orally to rats by Gillman and Gilbert (13). Such vascular lesions were not observed in the present material, possibly because absorption of the sterol from its subcutaneous depot was limited and the duration of exposure short. Others have described involvement of all segments of the nephron in vitamin $\mathrm{D}$ poisoning (13-15); in some reports the collecting ducts are noted as particularly affected $(16,17)$. The lesions in the collecting ducts which were observed in the present study may represent the earliest morphological changes of calciferol intoxication.

The severe reduction in concentrating ability sustained by hypercalcemic rats contrasts with their relatively well-maintained blood urea nitrogen, urea clearance, and ability to excrete PSP. To the extent that these parameters reflect the same functions in the rat that they do in man and the dog, these data suggest that concentrating ability was impaired out of proportion to changes in glomerular filtration and proximal tubular secretory function. This functional pattern is similar to that observed in humans depleted of potassium (18). It is unlikely that the animals of the present study were potassium-deficient, since their diet contained liberal amounts of potassium, they did not have diarrhea and their serum potassium was normal. Moreover, the same functional and morphological changes were observed when the diet was supplemented with potassium.

Micropuncture studies suggest that the final site of water reabsorption and urinary concentration lies in the collecting ducts and that the motive energy for this process is derived from the reabsorption of sodium from more proximal portions of the nephron and its concentration in the interstitial fluid of the medulla (19). It is therefore of great interest that the lesions observed in the present study were chiefly localized to the collecting tubules. The marked decrease in concentrating power contrasts with the fact that microscopic evidence of injury was generally sparse (indeed, absent in Rat No. 1). This suggests that in many collecting ducts injury had progressed to a degree sufficient to interfere with function though too subtle to be detected morphologically; in those areas where injury was sufficiently intense or prolonged, necrosis occurred with attempted repair by proliferation.

These findings may be interpreted in the light of current theories of urinary concentration and the action of antidiuretic hormone. It might be supposed, for example, that diffusion of water out of the collecting ducts, normally enhanced by vasopressin, is slowed by injury to the cells and/or the basement membranes lining these tubules. Alternatively, hypercalcemia and/or increased intracellular concentrations of calcium might impair the efficiency of the mechanism by which sodium is pumped out of the loops of Henle and concentrated in the medulla (20). In this connection it is interesting that infusions of calcium salts are reported to increase the renal excretion of sodium $(21,22)$.

The functional and morphological similarities between the lesions of potassium deficiency in the rat $(23,24)$ and those observed in the present study are noteworthy. Both are characterized by spotty necrosis and hyperplasia localized chiefly to tubular cells in the outer medulla, although the lesions observed in rats kept on a potassium-free diet for three to six weeks are more numerous than those of the present report $(24,25)$. Both are associated with a depression of renal concentrating ability out of proportion to other tests of renal function. These facts are reminiscent of the opposing effects of potassium and calcium on neuromuscular behavior (26). It is tempting to speculate that these are examples of a general phenomenon, and that the activity of cell enzymes or the permeability of cell membranes in many organs, including the kidney, may be altered in the same direction by depletion of potassium or a surfeit of calcium.

The present results demonstrate that vitamin $\mathrm{D}$ intoxication of short duration and mild degree specifically impairs renal concentrating ability in rats and suggest that similar alterations in renal structure and function may be responsible for the polyuria previously observed in a variety of clinical states associated with hypercalcemia or nephrocalcinosis. 


\section{SUM MARY}

Hypercalcemia was induced in rats by four daily injections of 200,000 to 400,000 units of calciferol. Renal concentrating ability was markedly impaired, although there was little or no change in blood urea, urea clearance or the excretion of phenolsulfonphthalein. Morphological changes in the kidneys were sparse and consisted chiefly of lesions involving the collecting ducts in the outer medulla. It is suggested that similar alterations in renal structure and function may be responsible for the polyuria and hyposthenuria observed in a variety of clinical states associated with hypercalcemia or nephrocalcinosis.

\section{REFERENCES}

1. Daeschner, C. W., Moyer, J. H., and Pfeiffer, E. M. Renal hemodynamic studies in patients with extensive paralysis. J. chron. Dis. 1958, 7, 43.

2. Anning, S. T., Dawson, J., Dolby, D. E., and Ingram, J. T. The toxic effects, of calciferol. Quart. J. Med. 1948, 17, 203.

3. Klatskin, G., and Gordon, M. Renal complications of sarcoidosis and their relationship to hypercalcemia, with a report of two cases simulating hyperparathyroidism. Amer. J. Med. 1953, 15, 484.

4. Cohen, S. I., Fitzgerald, M. G., Fourman, P., Griffiths, W. J., and deWardener, H. E. Polyuria in hyperparathyroidism. Quart. J. Med. 1957, 26, 423.

5. Hellström, J. Primary hyperparathyroidism. Observations in a series of 50 cases. Acta endocr. (Kbh.) 1954, 16, 30.

6. Mawdsley, C., and Holman, R. L. Hypercalcaemia in acute leukaemia. Lancet 1957, 272, 78.

7. Swyer, A. J., Berger, J. S., Gordon, H. M., and Laszlo, D. Hypercalcemia in osteolytic metastatic cancer of the breast. Amer. J. Med. 1950, 8, 724.

8. Dorhout Mees, E. J. Disturbed water-reabsorption by the renal tubules in two patients with hypercalcaemia. Acta med. scand. 1957, 157, 199.

9. Hayman, J. M., Jr., Shumway, N. P., Dumke, P., and Miller, M. Experimental hyposthenuria. J. clin. Invest. 1939, 18, 195.

10. Conway, E. J. Microdiffusion Analysis and Volumetric Error, 3rd rev. ed. London, C. Lockwood, 1950.

11. Tisdall, F. F. A note on the Kramer-Tisdall method for the determination of calcium in small amounts of serum. J. biol. Chem. 1923, 56, 439.

12. Eisenstein, R., and Groff, W. A. Experimental hypervitaminosis D: Hypercalcemia, hyperneucopro- teinemia, and metastatic calcification. Proc. Soc. exp. Biol. (N. Y.) 1957, 94, 441.

13. Gillman, J., and Gilbert, C. Periarteritis and other forms of necrotising angeitis produced by vitamin $D$ in thyroxinised rats with an assessment of the aetiology of these vascular lesions. Brit. J. exp. Path. 1956, 37, 584.

14. Shohl, A. T., Goldblatt, H., and Brown, H. B. The pathological effects upon rats of excess irradiated ergosterol. J. clin. Invest. 1929-30, 8, 505.

15. Goormatigh, N., and Handovsky, H. Effect of vitamin $D_{2}$ (calciferol) on the dog. Arch. Path. (Chicago) 1938, 26, 1144.

16. Kent, S. P., Vawter, G. F., Dowben, R. M., and Benson, R. E. Hypervitaminosis D in monkeys; a clinical and pathological study. Amer. J. Path. 1958, 34, 37.

17. Steck, I. E., Deutsch, H., Reed, C. I., and Struck, H. C. Further studies on intoxication with vitamin D. Ann. intern. Med. 1937, 10, 951.

18. Relman, A. S., and Schwartz, W. B. The nephropathy of potassium depletion, a clinical and pathological entity. New Engl. J. Med. 1956, 255, 195.

19. Wirz, H. Der osmotische Druck in den corticalen Tubuli der Rattenniere. Helv. physiol. pharmacol. Acta 1956, 14, 353.

20. Berliner, R. W., Levinsky, N. G., Davidson, D. G., and Eden, M. Dilution and concentration of the urine and the action of antidiuretic hormone. Amer. J. Med. 1958, 24, 730.

21. Levitt, M. F., Halpern, M. H., Polimeros, D. P. Sweet, A. Y., and Gribetz, D. The effect of abrupt changes in plasma calcium concentrations on renal function and electrolyte excretion in man and monkey. J. clin. Invest. 1958, 37, 294.

22. Freedman, P., Moulton, R., and Spencer, A. G. The effect of intravenous calcium gluconate on the renal excretion of water and electrolytes. Clin. Sci. 1958, 17, 247.

23. Hollander, W., Jr., Winters, R. W., Williams, T. F. Bradley, J., Oliver, J., and Welt, L. G. Defect in the renal tubular reabsorption of water associated with potassium depletion in rats. Amer. J. Physiol. 1957, 189, 557.

24. Oliver, J., MacDowell, M., Welt, L. G., Holliday, M. A., Hollander, W., Jr., Winters, R. W., Williams, T. F., and Segar, W. E. The renal lesions of electrolyte imbalance. I. The structural alterations in potassium-depleted rats. J. exp. Med. 1957, 106, 563.

25. Carone, F. A., Kashgarian, M., and Epstein, F. H. Unpublished data.

26. Brink, F., Jr., Bronk, D. W., and Larrabee, M. G. Chemical excitation of nerve. Ann. N. Y. Acad. Sci. 1946, 47, 457. 